THE ECONOMIC THEORY OF 'MANAGERIAL' CAPITALISM 
Books by the same author

*

ECONOMIC ARITHMETIC 


\title{
THE ECONOMIC THEORY OF
}

\section{'MANAGERIAL’ CAPITALISM}

\author{
BY \\ ROBIN MARRIS \\ FELLOW OF KING'S COLLEGE, CAMBRIDGE
}

\section{Palgrave Macmillan I 964}




\author{
ISBN 978-1-349-81734-4 ISBN 978-1-349-81732-0 (eBook) \\ DOI 10.1007/978-1-349-81732-0 \\ Copyright (C) Robin Marris, 1964
}

Softcover reprint of the hardcover 1st edition 1964 978-0-333-04985-3

MACMILLAN AND COMPANY LIMITED

St Martin's Street London WC2

also Bombay Calcutta Madras Melbourne

THE MACMILLAN COMPANY OF CANADA LIMITED

Toronto 
To

JANE 


\section{CONTENTS}

The Disappearance of the Entrepreneur. The Traditional Pre-History of a Corporation. The Corporate Collective. The Influence of the Stock Market. A Theory of TakeOver. The Concept of Sustainable Growth. Growth which is both Sustainable and Safe. 'Managerial' Take-Over and the Constrained Valuation Ratio.

\section{Motives ANd Morals}

Introduction and Survey of the Chapter. Theories of Motivation. Psychological Motives. Sociological Motives. A Norm of Professional Competence. Economic Motives. An Analysis of Bonus Schemes. Stock-Option Plans. Basic Compensation. The Simon Theory. Policy Implications of a 'Bureconic' Theory. Generalisation of the Growth Motive. A Managerial Utility System. Maximising, Satisficing and Behaviourism.

\section{Concepts and Methods}

Characterisation of the Firm. The Internal Restraint on the Growth-Rate. The Concept of Balanced or Sustainable Growth. The Role of Diversification. The Role of Merger. The Economic Environment. Methods of Analysis. Further Definitions.

4. 'Demand'

The Consumer and His Brain. The Process of Want Creation. The Pioneering Consumer. The Chain Reaction. Socio-Economic Structure. Social Barriers and Social Bars. Chain Reactions in Intermediate Products. A Mathematical Model of the Socio-Economic Structure. The Conditions for Criticality. Growth and Profitability. A Probabilistic Model. Growth by Imitation. The Bandwaggon Strategy. Static Markets. General Implications of Imitative Strategy. Non-Diversifying Growth. Empirical Support. Glossary of Symbols. 
5. 'Supply'

Outline of the Problem. The Basic Equation. Maximising Procedure, First Stage. New Issues, Retentions and Market Valuation. Theories of Asset Holding. Maximising, Second Stage. Effects of a Variable Constraint. Econometric Support.

6. Completed Micro-Models

Model I: Policy Model for Growth-Rate Maximisation Subject to Minimum Security Constraint. Diagrammatic Analysis. A Mathematical Version. Economic Implications. Model 2: Preliminary Account. The Valuation Curve. Economic Interpretation. Maximising Managerial Utility.

7. Behaviour and Evidence

Satisficing and All That. Econometric Support.

8. Possible Macro Implications

Working Assumptions. The Aggregate Retention Ratio. Natural and Quasi-Natural Rates of Growth. Inflexible Growth Rate and Fully Restricted Thrift. Inflexible Growth Rate, Thriftiness partly Restricted. A FlexibleGrowth Model.

Notes

LIST OF REFERENCES

INDEX

List of EQuations (other than Chapter 4) 


\section{LIST OF ILLUSTRATIONS}

\section{DiAGRAMS}

I.I Boundary of Safe Policies with Negative Return Discrepancy

I.2 Safe and Sustainable Policies

2.I Standard Organisational Pyramid with Constant Span of Control

4.I Primary Groups in a Linear Suburb .

4.2 Net-Like Structure of Primary Groups

4.3 Demand Curve for a Saturated Product

6.I Family of Demand-Growth Curves

6.2 Internal-Efficiency Relation

6.3 Family of Finance-Supply Curves

6.4 Balanced-Growth Curve

6.5 Demand Curve and Iso-Valuation Line

6.6 Valuation Curve and Managerial Indifference Curve

\section{TABLeS}

6.I Characteristic Magnitudes of Coefficients in Mathematical Version of Model I

6.2 Summary of Qualitative Relationships in Model I

6.3 Typical Results in Model I

6.4 Values of Variables at Various Positions on Demand Curve and Valuation Curve

7.I Summary of Predictions for Various Disturbance Types

7.2 Meyer and Kuh Correlation Patterns

7.3 Signs and Magnitudes of Correlation Coefficients in Myron Gordon Data 


\section{INTRODUCTION AND PREFACE}

This essay was inspired by a growing sense of frustration at the divorce between the motivational axioms employed in the established micro-economic theories and the type of behaviour most believe to be real. We drill our students in analytical exercises based on these theories. We warn them not to believe the assumptions, but offer only incompletely developed alternatives. By the same token applied research is weakened.

Yet ever since the publication of 'Berle and Means' most of the profession has recognised the existence of some kind of 'managerial' capitalism based on separation of ownership from control. Some have argued that in practice this system behaves little differently from 'traditional' capitalism. Others have asserted the opposite. And recently one or two writers have suggested plausible models based on more appropriate assumptions. So far, however, such models have not been worked out in great detail or integrated into comprehensive theories of the firm.

We therefore feel justified in attempting to carry the development a stage further. We start from the proposition that corporate directors may subject corporate policy decisions to utility functions of their own. We ask after the probable nature of the resulting preference system, given the character of the institutional environment and the nature of the managerial task. We also consider the extent to which the environment will permit such preferences to count. These foundations are then employed in an attempt to reconstruct the 'internal' theory of the firm.

A summary of one of the resulting models appeared in the Quarterly Fournal of Economics in May 1963, but the reader is warned that the author's ideas have developed considerably since that paper was written. In this book, the first two chapters discuss the inter-relationship between institutional framework and utility system, always against the background of the existence of an organised market for corporate securities. The third chapter relates the results of the first two to the conventional economic environ- 
ment, defines concepts and explains the analytical methods to be employed later. The next three chapters work out two specific micro-models, which at the end of the sixth are more or less integrated into a single final model. Chapter 7 attempts to apply the models to real behaviour, taking account of known statistical evidence. Finally, Chapter 8 ventures to speculate about possible macro-implications.

On the empirical side we have drawn heavily from existing material, both qualitative and econometric. We also deploy the results of some limited experiments of our own. But the main weight of testing must await the results of a substantial programme of research based on the analysis of ten years of data derived from the accounts of all British quoted companies, which is currently in progress at the Cambridge University Department of Applied Economics. We make no apology whatsoever for publishing the theory in advance.

So many people on both sides of the Atlantic have contributed criticism and advice that it is difficult to guarantee that acknowledgements will be adequately comprehensive. A significant debt is owed at least to all of the following economists and associated institutions:

Kenneth Arrow, A. K. Bagchi, Lee Bawden, William Baumol, Alan Brown, Robert Dorfman, James Duesenberry, Christopher Farrow, Sargent Florence, Gordon Fisher, Aaron Gordon, Frank Hahn, P. E. Hart, Benjamin Higgins, Herschel Kanter, Carl Kaysen, Richard Kahn, Nicholas Kaldor, Harvey Leibenstein, John Lintner, Siro Lombardini, Fritz Machlup, Julius Margolis, John Meyer, Luigi Pasinetti, Michael Posner, Jack Revell, Joan Robinson, Janet Rothenberg, Richard Ruggles, Eugene Rostow, David Snell and Peter Wiles; members of the staff seminar of the Economics Department, University of Texas, fall I960; members of the author's graduate classes at Berkeley in $196 \mathrm{r}$; seminarists at Harvard, Princeton, Texas A \& M, UCLA and Yale in 1960 and I96I ; a group of economists in Cambridge, England; The Institute of Business and Economic Research at Berkeley. Mrs. Robinson, however, must be singled out for especial thanks. She has given constant support, encouragement and constructive criticism, and 
her recent thinking has almost certainly had a considerable influence on the author's.

Another name for special mention is that of Ajit Singh. Acting as the author's assistant, first in Berkeley and later in Cambridge, he not only carried out the econometric work described in Chapter 2, but also read the whole final manuscript, corrected many errors and revised certain passages. The author is greatly in his debt for most efficient and perceptive advice.

Among persons associated with disciplines other than economics, we should mention Noel Annan, John Goldthorpe and Bill Wedderburn. Dr. Goldthorpe's sociological contribution, which resulted from a collaboration between himself and the author in a course of lectures given in Cambridge, was particularly important, as will be apparent to any reader who gets as far as Chapter 2.

Appreciation should also be expressed to the Fulbright Commission and to the Departments of Economics at the Universities of Texas and California (at Berkeley) for facilitating the author's visit to the U.S. in 1960 and thus materially assisting in the research. To the then Chairman of the former Department, Ben Higgins, thanks are due for advice, encouragement and the provision of captive audiences; to the then Chairman of the latter, Aaron Gordon, thanks are due not only for giving the benefit of his very considerable experience in this field, but also for lending his substantial stock of research material connected with the Preface to the 196r edition of Business Leadership.

Finally, if the book is readable, this is entirely the responsibility of the author's wife, who being, unlike himself, literate, has struggled womanfully over a long period to improve the prose. What more could a man ask? 


\section{NOTE ON CONCEPTS AND}

\section{DEFINITIONS}

THE concepts and symbols used in this book are usually defined in the text only once, where they first appear, but a glossary is provided on page 347 . Here, by way of introduction, we describe the general method of notation and also name and define some basic accounting conventions. These methods and conventions are not explained in the text and the reader is recommended to study them before starting the first chapter.

\section{Symbols}

In general we use upper case English letters for original variables, lower case English letters for ratios. The Greek letters, $\alpha, \beta, \gamma$, etc. are used for coefficients, $\pi, \rho, \sigma$, etc. for special variables and the symbols $\delta$ and $f$ for the usual operators. (The letter $d$, however, is needed for a nominative symbol.) With the exception of coefficients, which may change definition between models, a symbol usually holds its basic meaning throughout the book, subject only to small modifications indicated in context.

An exception to the foregoing is found in the treatment of empirical regression equations: for these we use the standard notation, $Y$ signifying the dependent variable, $a$ the constant, $X_{1}, X_{2}$, etc., the determining variables and $b_{1}, b_{2}$, etc., the corresponding regression coefficients obtained by the method of leastsquares; we also adopt the usual procedure of indicating the standard error of a regression coefficient by $\mp$ following the estimate; then $t$ is the ratio of estimate to standard error and $R$ is the multiple correlation coefficient. Outside the context of a regression model these symbols may be used for other purposes (e.g. $t$ may stand for time and $R$ stands for an accounting concept mentioned below).

Another exception is found in the notation of Chapter 4 ('Demand'). This is entirely separate from the rest and symbols used elsewhere may 
here be used quite differently. A special glossary is provided at the end of the chapter.

As already indicated, a glossary of frequently recurring symbols other than those used in Chapter 4 is provided on the last page, after the index. We also provide a list of equations, in order of occurrence, each equation being restated with an indication of the page on which it first appeared.

\section{Operators}

In addition to those mentioned above, three other operators are employed, one relating to constraints, one to optimum values and one to growth rates, apologies being due for the last which is unconventional.

(i) Constraints: a bar placed over a symbol signifies a constrained maximum or minimum value of the corresponding variable according to context.

(ii) Optimum Values: an asterisk placed to the side of a symbol signifies the maximum value subject to constraints or other conditions specified; an asterisk so placed when associated with a bracketed suffix, however, signifies the value of this variable required to maximise another variable indicated in the suffix.

(iii) Growth rates: A dot placed above and to the right of a symbol signifies a proportional time rate of change. More precisely,

$$
X^{\cdot}=\frac{d \log X}{d t}
$$

and hence $X^{* \bullet}$ indicates maximum $X^{\bullet}$ or, loosely, maximum growth rate. The Newtonian operator, with dot placed directly above the symbol, is not employed, and in the rare cases where we have need of $d x / d t$, this is printed in full.

\section{Numbering}

'Equations' (i.e. any formulae containing equalities, inequalities or both), and also diagrams, are numbered by chapters on the Dewey system, footnotes (printed at the end of the book) by chapters in the ordinary manner. 


\section{Accounting Conventions}

The following conventions and definitions relate to individual joint stock companies whose securities are quoted on a recognised Exchange, in other words to the basic subjects of our enquiry.

Book Value: the original cost of an asset, less the proportion of original value deemed by the firm's accountants to have been lost through depreciation, adjusted for any change in the supply price of assets of this technical description and performance which may have occurred since it was installed. It should be noted that the concept is employed primarily to measure physical capacity.

Gross Assets: Fixed Assets at Book Value (see above), Inventory, Securities at market value, Cash and Net Trade Credit (Symbol: $C$; the concept is also loosely referred to as 'capital', 'capital employed', 'corporate capital', or simply 'book value').

Debt: Debentures, par value of cumulative non-voting preference shares and net short-term liabilities. (No symbol, but ratio of debt, less liquid assets, to gross assets, called the 'leverage' or 'gearing' ratio, is signified by $g$.)

Net Assets: Gross Assets less Debt (no symbol).

Liquid Assets: Securities, plus cash in excess of minimum working balance (no symbol).

Productive Assets: Gross Assets less Liquid Assets (no symbol). It should be noted that, as defined, the concept includes not only book value of fixed assets but also other non-fixed assets normally required for trading activity, such as minimum cash, inventory and credit to customers. Hence, given the method of valuation, so long as their technical character and supply price are constant, variations in the magnitude of productive assets may be regarded as synonymous with variations in productive capacity.

Profits: Trading profits net of depreciation and tax, plus nontrading income net of tax (Symbol: $P$ ). The appropriate tax deduction depends on the method of taxing companies in the country concerned, but in principle should not include elements of personal income tax being collected at source. In the U.K. the deduction would therefore be income tax on undistributed profits plus Profits Tax, in the U.S. it would be corporate profits tax only. 
xviii NOTE ON CONCEPTS AND DEFINITIONS

Internal Rate of Return: the ratio of Profits to Gross Assets (Symbol: $p$; concept is also referred to as rate of profit or rate of return).

Earnings: Profits less interest on debt and dividends on preference shares included in debt (no symbol).

Retained Earnings: Earnings less Dividends on Ordinary Stock and any other shares not included in debt.

Retention Ratio: Ratio of Retained Earnings to Earnings (Symbol: r).

Net rate of return: ratio of Earnings to Net Assets (Symbol: $p^{\prime}$ ).

Par Value: Aggregate par value of all issued securities not included in Debt (Symbol: $N$ ).

Market Value: Aggregate of all issued securities not included in debt, valued, except where otherwise indicated, at the current market quotation (no symbol, but ratio of Market Value to Net Assets, called the 'valuation ratio', is signified by $v$ ). 